\title{
ASSISTENNCIA DE ENFERMAGEM A PACIENTES COM COMPORTAMENTO CARACTERIZADO POR MANIFESTAÇÕES DE AGITAÇĀO E AGRESSIVIDADE
}

\author{
Marina Borges Teixeira* \\ Maguida Costa Stefanelli * \\ Evalda Cançado Arantes**
}

TEIXEIRA, M. B.; STEFANELli, M. C.; ARANTES, E. C. Assistência de enfermagem a pacientes com comportamento caracterizado por manifestações de agitação e agres. sividade. Rev. Esc. Enf. USP, São Paulo, 15(2):141-146, 1981.

As autoras apresentam aspectos gerais da assistência de enfermagem para atender pacientes com manifestações de agitação e agressividade, com o objetivo de preservar a integridade física e psíquica destes, das pessoas que o rodeiam e o desenvolvimento do controle sobre seu comportamento.

\section{INTRODUÇÃO}

As manifestações de comportamento que mais despertam atenção num hospital psiquiátrico são as de agitação e agressividade, tanto nas unidades de internação como nas unidades de atendimento ambulatorial. Estas manifestações, em geral, são as que caracterizam, para o leigo, o hospital psiquiátrico, talvez por serem manifestações exuberantes ou que podem oferecer riscos à integridade tanto da pessoa que as apresenta como das que a rodeiam.

A agitação, segundo POROT (1977), é essencialmente uma forma da pessoa se conduzir. É a expressão motora, mais ou menos turbulenta e desordenada, em que a pessoa, com atos sem reflexão, dá vazão a impulsos instintivos ou afetivos variáveis, segundo as circunstâncias patológicas em que se encontra.

SANTO-DOMINGO CARRASCO (1968) afirma que a agitação comporta dois aspectos: um motor, no qual a pessoa agitada movimenta-se excessivamente, outro psicológico, que repercute em todas suas funções psíquicas e no qual parece que a pessoa só percebe o que a interessa ou a excita.

A agitação pode ou não estar acompanhada de agressividade. Nem toda pessoa que apresenta manifestações de agitação torna-se agressiva.

Para SANTO-DOMINGO CARRASCO (1968), COLEMAN (1973), DORIN (1978) e BAILEY \& DREYER (1977), entre outros, a agressividade é uma forma da pessoa comportar-se resultante de frustrações.

LINN (1980) define a agressão como uma constelação de pensamentos, sentimentos e ações específicas que são mobilizados por uma barreira a um desejo ou necessidade e com objetivo de removê-la, permitindo o direcionamento das manifestaçōes de comportamento.

\footnotetext{
* Professor Assistente da disciplina Enfermagem Psiquiátrica da EEUSP. Mestre em Enfermagem.
}

* * Professor Assistente Doutor da disciplina Enfermagem Psiquiátrica da EEUSP. 
As manifestações de agitação e agressividade aparecem em vários quadros psiquiátricos: psicose maniaco-depressiva (fase de mania), esquizofrenia, psicose epilética; aparecem também nos quadros confusionais, entre outros.

As manfestações características de agitação e agressividade ocorrem com maior freqüência em pacientes na fase de mania da psicose maníaco-depressiva. As manifestações de comportamento, como ocorrem nesta fase, serão o objeto da assistência de enfermagem do presente artigo. Para tanto, além das manifestações de agitação e agressividade, serão consideradas, também, outras manifestações de comportamento decorrentes da psicopatologia da psicose maníaco-depressiva, fase de mania.

\section{ASSISTÊNCIA DE ENFERMAGEM}

A incapacidade do paciente utilizar mecanismos de defesa para controlar sua agitação e agressividade pode gerar inúmeros problemas, tanto para ele como para a assistência de enfermagem.

O paciente não se considera doente e, portanto, não aceita internação e tratamento. A sua incapacidade de controlar suas manifestações de agitação e agressividade provoca medo e rejeição nos que o rodeiam, o que gera exacerbação daquelas manifestações. Como conseqüência, surge desrespeito às rotinas, agressão a objetos, a ele próprio ou a outras pessoas. Quando o paciente percebe a situação por cle provocada fica ansioso. No momento em que está em condições de avaliar seus atos, ele pode expressar sentimentos idepressivos e de culpabilidade podendo, também, chegar até a tentativa de auto-eliminação.

Os problemas que as pessoas da equipe de enfermagem encontram ao cuidar do paciente são decorrentes, na maioria, da atitude das mesmas em relação às manifestações de agressividade. Esta atitude norteia sentimentos em relação ao paciente agressivo.

A impossibilidade do paciente em manter-se atento a um único estímulo, não permite que ele atenda as solicitações, obedeça às imposições de limite e fixe as orientações recebidas. Isto acaba por gerar irritação e rejeição nos demais pacientes e no pessoal que o atende.

Impedir a formação de grupos de pacientes com comportamento semelhante e preservar a integridade do paciente edos demais, também constituem problemas para a equipe de enfermagem.

Quando as pessoas que assistem o paciente necessitam tomar medidas mais drásticas para conter o comportamento do mesmo, podem surgir naquelas, sentimentos de culpa e de impotência que são considerados problemas, uma vez que estes sentimentos geram ansiedade.

A análise dos problemas do paciente e do pessoal de enfermagem mostra que a assistência de enfermagem deve ter como objetivos primordiais a preservação da integridade do paciente e dos demais e o desenvolvimento de controle sobre suas próprias manifestações de comportamento. 
0 primeiro passo para atuação efetiva por parte do enfermeiro, ao cuidar deste paciente, é analisar seus sentimentos em relação às manifestações de agitação e agressividade e os seus padrões habituais de comportamento em face destas. Isto facilita à pessoa que presta assistência de enfermagem, o desenvolvimento do auto-domínio, mesmo quando o paciente faz comentários sarcásticos sobre sua pessoa ou sobre seu desempenho profissional.

0 enfermeiro deve procurar orientar e auxiliar os membros de sua equipe na compreensão do comportamento do paciente, para evitar a irritação e rejeição que este provoca; deve-se igualmente respeitar o espaço de tempo em que cada funcionário é capaz de controlar sua própria ansiedade em face desse tipo de comportamento. São recomendadas também reuniōes diárias para discussão da atuação do pessoal da equipe de enfermagem, dos problemas encontrados e da evolução do comportamento do paciente.

A observação constante e o relato das manifestações de comportamento do paciente é que fornecem aos membros da equipe de enfermagem, parâmetros para perceber quando, como e porquê as manifestações de agitação e agressividade são iniciadas. Se possivel, a equipe de enfermagem deve obter dos familiares dados a respeito das manifestações de comportamento do paciente antes da percepção do início da doença e da internação, a fim de que tenha elementos mais concretos para prevenir a agitação e agressividade. $O$ pessoal da equipe precisa manter $o$ paciente sob vigilância constante, tendo sempre em mente que ele é um suicida em potencial porque, de acordo com as característias da própria doença, ele pode entrar na fase de depressão da psicose maníaco-depressiva sem que esta seja identificada prontamente.

Em relação ao ambiente do paciente, que deve ser o mais tranqüilo possível, com o minimo de estímulos, algumas medidas devem ser tomadas, a saber: paredes em tom pastel, música ambiente suave, mobiliário estritamente necessário, de bordos arredondados, sem objetos que sirvam para auto e hetero agressão.

O paciente que apresenta o quadro em estudo deve, de preferência, permanecer em local com poucos pacientes; estes devem ser orientados sobre o comportamento dele. É desaconselhável colocá-lo junto com pacientes deprimidos, porque o comportamento do paciente os irrita e vice-versa; é, ainda, de bom alvitre, separá-lo de pacientes com o mesmo tipo de manifestaçōes de comportamento, para que sejam evitadas aumento de excitação e possível ocorrência de injúrias físicas; devido à agitação psicomotora é aconselhável que este paciente tenha como local de repouso, na fase aguda, quarto individual.

Ao conversar com o paciente, o enfermeiro deve sempre falar em tom baixo de voz, porém audível, para evitar aumento da excitação do paciente, usar frases curtas e linguagem clara devido à dificuldade do paciente em fixar a atenção.

Outra medida, que surte resultado eficaz, impedindo exacerbação das manifestações de comportamento é a promoção de atividades que ocupem o paciente, de forma a canalizar sua energia excessiva para uma atividade útil ou pelo menos inofensiva tanto para ele como para os demais. Estas não devem ter caráter competitivo, nem exigir esforço de concentração ou tempo demasiado para sua execução e devem ser de fácil conclusão como, por exemplo, limpar pisos e paredes, 
arrumar camas, dobrar roupas; em resumo, atividades que permitam movimentos amplos, sem minúcias.

Como o paciente não demonstra cansaço, o enfermeiro deve planejar com ele suas atividades, de tal forma que as horas de sono e repouso sejam respeitadas, para evitar quadro de estafa. A idéia primordial é que a atividade do paciente seja usada para o desenvolvimento de controle sobre suas manifestações e não para prestação de serviços.

Quando essas medidas citadas não são suficientes para controlar a agitação e agressividade do paciente, o enfermeiro tem que recorrer a outras formas de limites. Para isso deve manter material de contenção e medicamentos, de acordo com prescrição médica, em local de fácil acesso e do conhecimento de todos que atuam na unidade.

Alguns cuidados devem ser tomados quando se tornar necessário isolar o paciente e fazer contenção física ou química: nunca enfrentar o paciente sozinho, estar sempre acompanhado de mais funcionários, agir rapidamente, pois quanto mais rápida a ação, maior segurança há para o paciente; usar de tato quando estes tipos de limites forem colocados, deixando claro ao paciente o que será feito e o porquê dos mesmos, sem reprovar seu comportamento. 0 enfermeiro, com estas medidas, estará atingindo outro aspecto fundamental da assistência de enfermagem a esse paciente, que é a aceitação dele como ser humano, qualquer que seja a manifestação de seu comportamento.

0 paciente deve ficar isolado ou contido somente durante o tempo estritamente necessário; quando receber medicação sedativa, a restrição deve ser retirada assim que aquela atingir o efeito desejado.

Com estas medidas é possivel oferecer ao paciente um clima de segurança, no qual lhe é permitido exibir determinadas manifestações de comportamento que não seriam aceitas em outro tipo de ambiente.

Como o paciente não se considera doente, o enfermeiro tem que orientá-lo, de forma clara e simples, sobre a necessidade da internação e tratamento, repetindo a orientação tantas vezes quantas forem necessárias, sem demonstrar irritação.

Quando o paciente apresentar aceleração do curso do pensamento, falar rapidamente, mudar de um assunto para outro, não conseguir expressar suas idéias com clareza e não terminar as frases que inicia, o enfermeiro deve ouvi-lo e ajudá-lo a expressar-se, tentando manter seu discurso coerente.

Quando manifestar idéias de grandeza, como quando afirma que é o melhor em tudo ou que nada é problema para ele, o enfermeiro deverá ouví-las, não discutí-las, nem alimentá-las, desviando a atenção do paciente para assuntos ou fatos que estejam ocorrendo no momento. Assim que o paciente tiver condições, o enfermeiro deve ajudá-lo a analisar suas idéias de forma realística, estando sempre atento para não fazer comentários que tenham conotação de reprovação, pois esta poderá gerar ou aumentar sentimentos de culpa no paciente.

Tendo em vista as manifestações jocosas e teatrais do paciente, com o comportamento em estudo, o enfermeiro não deve permitir situações nas quais ele 
possa tornar-se alvo de zombaria; se o paciente estiver eufórico, falando loquazmente, deve ter cuidado para não excitá-lo ainda mais. Procurar afastá-lo dos demais, conversar em tom baixo de voz, denotar tranqüilidade, são medidas indicadas nesta situação.

Quando o paciente se despe, usa termos de baixo calão ou faz propostas indecorosas aos demais, o enfermeiro deve impor limites, dizendo-lhe de forma clara que estas manifestações de comportamento não são aceitas e, ao mesmo tempo, estar atento para evitar que os outros pacientes o agridam.

A agitação psicomotora não permite que o paciente cuide de sua higiene $e$ aparência. $O$ enfermeiro deve levá-lo para o banho diariamente e, se necessário, mais vezes ao dia; supervisioná-lo e orientá-lo para que se lave, se enxugue, se vista adequadamente, faça sua higiene oral e mantenha suas unhas sempre limpas e aparadas para evitar ferimentos e infecções.

Não deve ser esquecido que a euforia e a agitação levam o paciente a se esquecer de ir ao sanitário para evacuar ou urinar e que, às vezes, urina e defeca nas vestes; é preciso que ele seja levado ao sanitário, a intervalos regulares, e que suas vestes sejam trocadas tantas vezes quantas forem necessárias. Evitar-se-ão, assim, efeitos desagradáveis como bexigona, fecaloma e infecções.

Apesar da agitação psicomotora provocar no paciente grande desgaste físico, ele não se detém para ingerir líquidos ou alimentos adequadamente; suco, leite e água devem ser-lhe oferecidos várias vezes ao dia, a fim de evitar desidratação. Há necessidade de se providenciar dieta fracionada, hiperprotéica, hipercalórica, rica em resíduos para repor suas energias e auxiliar a motilidade intestinal, pois estes pacientes têm tendência à obstipação.

0 enfermeiro deve sentar-se ao lado do paciente no horário das refeições, procurando manter a atenção deste voltada para os alimentos; por vezes, é aconselhável oferecer-lhe alimentos em local isolado, ou porque o excesso de estímulo o irrita ainda mais, ou porque seu comportamento irrita os demais pacientes, provocando tumulto no refeitório. Caso essas medidas não surtam o efeito desejado, deve oferecer-lhe alimentos de fácil deglutição como sopas, mingaus, suco de frutas, ou alimentos sólidos na forma de sanduiche, frutas, bolachas, que possa comer enquanto se movimenta.

O enfermeiro deve estar atento para problemas somáticos do paciente, pois este não se preocupa com ferimentos, sintomas e sinais de doença somática e parece não sentir as mudanças na temperatura ambiente. Compete ao enfermeiro manter o paciente vestido adequadamente, observar edema de membros inferiores, ferimentos e tomar as medidas necessárias para cada caso. $O$ paciente deve ser pesado duas ou mais vezes por semana e seu peso deve ser comparado com o registrado no momento da internação.

O enfermeiro deve lembrar-se sempre de que as necessidades de sono e repouso do paciente não estão abolidas e tomar as providências necessárias.

À medida que começa a haver remissão das manifestações de comportamento, decorrentes dos sintomas apresentados pelo paciente, o enfermeiro deve procurar socializá-lo, induzindo-o, a princípio a desenvolver atividades com pequenos 
grupos de pacientes, até que ele demonstre ser capaz de participar adequadamente das atividades grupais.

Quando o paciente começar a analisar de forma realística as ocorrências da fase aguda da doença, o enfermeiro precisa estar atento para ajudá-lo a compreendier e a aceitar que naquela época ele não tinha condições de agir de outra forma, e que os incidentes e acidentes, que porventura tenha provocado, independeram de sua vontade.

$O$ apoio aos familiares do paciente não pode ser esquecido. Devem estes ser orientados quanto ao comportamento do mesmo e quanto ao porquê de determinadas manifestações de comportamento. Os familiares devem, também, ser orientados quanto à medicação que o paciente precisa tomar e quanto às manifestaçōes de comportamento a serem observadas como indícios de novo surto: insônia, anorexia, irritabilidade, manifestações de tristeza e de prodigalidade.

TEIXEIRA, M. B.; STEFANELLI, M. C.; ARANTES, E. C. Nursing care of patients with agitation and agressiveness manifestations. Rev. Esc. Enf. USP, São Paulo, 15(2): 141-146, 1981.

The authors describe the nursing care of patients with agitation and aggressiveness manifestations, in order to preserve their physical and psychic integrity, to protect the integrity of those around them and to help the patient control his own behavior.

\section{REFERENGIAS BIBLIOGRAFICAS}

BAYLEY, D. S. \& DREYER, S. O. Understanding the patient's diagnosis. In: approaches to the care of the mentally ill. Philadelphia, Davis, 1977. cap. 4, p. 58-60.

COLEMAN, J. C. A psicologia do anormal e a vida contemporânea. São Paulo, Pioneira, 1973. v. 1 p. $445-50$. DORIN, E. Diclonário de psicologia. São Paulo, Melhoramentos, 1978. p. 15-6.

LIN, L. Clinical manifestations of psychiatric disords. In: KAPLAN, H. I. et alii. Comprehensive text. book of psychiatry/11I. 3. ed. Baltimore, Willians \& Wilkins, 1980. v. 1, cap. 13, p. 1023.

POROT, A. Dlcionário de psiquiatria. 3. ed. Barcelona, Labor, 1977. v. 1, p. 46.

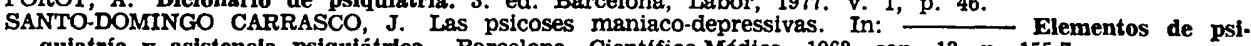
quiatría y asistencia psiquiátrica. Barcelona, Cientifico-Médica, 1968. cap. 13, p. 155-7.

\section{BIBLIOGRAFIA}

BAYLEY, D. S. \& DREYER, S. O. Aggressive patients. In: - Therapeutic approaches to the care of the mentally ill. Philadelphia, Davis, 1977. cap. 10, p. 137.47.

HOLBROOK, B. et alli. Agression: a diferent approach. Nurs. Mirror, London, 144 (16): 45-48, Apr. 1977. LION, J. R. et alli. Restraining the violent patient. J. Phych. Nurs., Thorofare, 10 (2): 9-11, Mar./Apr. 1972. MANFREDA, M. L. Moods of elation and depression in affective behavior: nursing care. In:

Psychiatric nursing. 5. ed. Philadelphia, Davis, 1977. cap. 34, p. 417-26.
MATHENEX, R. U. \& TOPALIS, S. M. Cuidado de los pacientes agressivos. In: - - Enfermeria psiquítrica. 5. ed. México, Interamericana, 1971. cap. 10, p. 145-62.

MERENESS, D. \& KARNOSH, I. J. LOS pacientes exaltados o deprimidos. In: - Elementos de enfermería psiquiátrica. México, Prensa Médica Mexicana, 1964. cap. 12, p. 152-61.

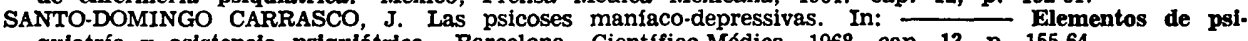

quiatria y asistencia psiquístrica. Barcelona, Científico-Médica, 1968. cap. 13, p. 155-64.
WOLPERT, E. A . Major affective disordes. In: KAPLAN, H. I. et alil. Comprehensive textbook of psychiatry/III. 3. ed. Baltimore, Willians \& Wilkins, 1980 .v. 2, p. 1319-32. 